Full length article

\title{
Who bears the brunt? The impact of banking crises on younger and older workers ${ }^{\text {is }}$
}

\author{
Mathijs A. van Dijk ${ }^{\mathrm{a}}$, Hendrik P. van Dalen ${ }^{\mathrm{b}, \mathrm{c}, \mathrm{d}, *}$, Martin Hyde ${ }^{\mathrm{e}}$ \\ ${ }^{a}$ Erasmus University Rotterdam, Rotterdam School of Management, P.O. Box 1738, NL-3000 DR Rotterdam, The Netherlands \\ ${ }^{\mathrm{b}}$ Tilburg University, Tilburg School of Economics and Management, CentER, P.O. Box 90153, NL-5000 LE Tilburg, The Netherlands \\ ${ }^{\mathrm{c}}$ Netherlands Interdisciplinary Demographic Institute (NIDI-KNAW), P.O. Box 11650, NL-2502 AR The Hague, The Netherlands \\ ${ }^{\mathrm{d}}$ University of Groningen, P. O. Box 72, NL-9700 AB Groningen, The Netherlands \\ e Swansea University, Centre for Innovative Ageing, Room 4, Haldane, Singleton Park, SA2 8PP Swansea, Wales, United Kingdom
}

\section{A R T I C L E I N F O}

\section{JEL codes:}

G0

J01

J08

J14

Keywords:

Banking crisis

Unemployment

Employment protection

Age

Older workers

Labor force

\begin{abstract}
A B S T R A C T
How do workers in different age groups fare on the labor market when a banking crisis occurs? Using data on 41 banking crises in 38 developed countries between 1990 and 2014, we examine how banking crises affect the labor market position of workers from five different age groups (including those aged 65 years and older) and whether employment protection legislation shields workers from unemployment. Results show that unemployment increases for all age groups in the aftermath of banking crises, but much more so for younger workers. The labor force participation of older women increases significantly in the medium run, whereas older men close to retirement withdraw from the labor market. Countries with strong employment protection legislation shield workers from the impact of banking crises in the short run but show signs of increases in unemployment rates for young and middle-aged workers in the medium run.
\end{abstract}

\section{Introduction}

How do younger and older workers fare in the labor market when banking crises occur? This simple question gained prominence during the Great Recession. The fall of Lehman Brothers in September 2008 set in motion a series of long run consequences, which at the time were clouded by uncertainty and speculation. It became soon clear that the credit crunch was real and affected many financial institutions around the world. But how exactly do banking crises affect the real economy? Problems within financial institutions are highly likely to translate into economic and societal consequences that will have to be borne by someone and the effects may be more long lasting compared to other forms of recession not caused by a banking crisis (Bernal-Verdugo et al., 2013). The consequences of a banking crisis can also cascade on to employers and employees outside of the financial industry. Dell'Ariccia et al. (2008) show that banking crises have an independent negative effect on the real economy as approximated by highly aggregated measures like real employment growth and value-added growth. However, these measures do not provide us with much detail on how different groups in society are affected.

A significant issue in countries undergoing population ageing is how different age groups in the labor market fare in the aftermath of a banking crisis. In this study, we assess how unemployment rates and labor force participation rates for different age groups of workers are affected by banking crises in 38 developed countries between 1990 and 2014. An important reason for specifically focusing on banking crises and not recessions in general is that banking crises tend to be longerlasting and more severe than normal recessions (which typically last less than a year; Reinhart and Rogoff, 2009a). This is because bank distress aggravates economic problems in other sectors through reduced access to credit (Dell'Ariccia et al., 2008). Furthermore, banking crises tend to be characterized by deep and prolonged collapses of housing and stock markets. In such circumstances, the unemployment consequences for households are even more important to understand, since

\footnotetext{
We thank Santanu Kundu, Huiming Zhang, Qingyuan Yang, and Jonas Elenskis for excellent research assistance. We are grateful for the hospitality of the

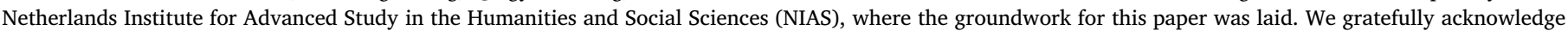
the constructive comments of three anonymous reviewers.

* Corresponding author at: Tilburg University, Tilburg School of Economics and Management, CentER, P.O. Box 90153, NL-5000 LE Tilburg, The Netherlands.

E-mail addresses: madijk@rsm.nl (M.A. van Dijk), h.p.vandalen@uvt.nl (H.P. van Dalen), Martin.Hyde@swansea.ac.uk (M. Hyde).
} 
households may simultaneously be exposed to these asset market shocks (Claessens et al., 2009). In this respect, banking crises offer a good testing ground for how different age groups, protected to various degrees by employment protection legislation, fare in the aftermath of a severe downturn. For example, in highly protected countries older workers may not experience any of the consequences of a normal recession.

The focus of this paper is on labor markets as one of the important macroeconomic transmission channels of a crisis. Two questions stand out: (i) which age group(s) of workers suffers most from a banking crisis in the short and medium run? and (ii) To what extent does employment protection legislation offer real protection from the impact of banking crises on unemployment?

Our analysis focuses on a sample of 38 countries over the period 1990-2014, for which we obtain yearly data on the occurrence of a banking crisis from Reinhart and Rogoff, 2009a, 2009b, 2011 and from Laeven and Valencia (2013) and yearly data on the unemployment rate and the labor force participation rate for men and women in five different age groups (15-24, 25-34, 35-54, 55-64, 65 and older). Over our sample period, these 38 countries experienced a total of 41 individual banking crisis periods. Although some of these crises are common across a number of these countries (such as the 2008-2009 crisis), many of the crises in our sample are limited to individual countries. Our main analyses are based on panel models with country and year fixed effects and a country-specific time trend that enable us to assess the impact of a banking crisis on unemployment and labor force participation in the year the banking crisis starts as well as the five subsequent years.

Consistent with prior studies (e.g., Dell'Ariccia et al., 2008; Scarpetta et al., 2010), we find that unemployment increases significantly and across the board in the aftermath of banking crises, but these effects are especially strong for the youngest workers. In particular, in the five years following the event of a banking crisis, youth unemployment (15-24) increases steeply, while the unemployment rate of older workers (55-64) increases at a far more modest rate. We find no significant effects for workers aged 65 and older. Across all age groups, the impact on male workers is greater than that for female workers. These unemployment effects are evident two years after the start of a crisis and escalate in subsequent years, generally peaking four years after the start of a crisis.

A connected question that we want to address is whether employment protection legislation (EPL) can mitigate the impact of banking crises on workers in different age groups. Using EPL data obtained from the OECD (see Venn, 2009), we make a distinction between countries with low and high employment protection. We find that the strength of EPL in a country experiencing a banking crisis affects unemployment outcomes significantly, with young and middle-aged workers more adversely affected in low protection regimes in the short run. Strikingly, there are some signs of a reversal of fortunes as time passes. Employees in low protection countries are hardly protected in the short run and tend to experience an increase in unemployment relative to those in high protection countries in the medium run. Conversely, young workers in high protection countries experience the downside of the crisis as their unemployment rate increases strongly in the medium run, relative to the peers in low protection countries. This suggests that EPL can soften the initial blow of a crisis but, once this has passed, it may be associated with economic costs as firms are forced to hold on to their workers and/or are reluctant to hire new workers. As a result, adaptations have to be made and firms may start restructuring or downsizing, leading to lower hiring rates and a longer unemployment duration for younger workers. Furthermore, whenever the effect of EPL becomes visible, one can see clear age patterns in protection: young workers (15-24 years) clearly have to bear the brunt of a banking crisis as their unemployment rate is higher than those of older workers, in particular in low protection countries.
The remainder of this paper is organized along the following lines. Section 2 reviews the evidence on how banking crises impact on the labor market, in theory and in the empirical literature. Section 3 describes the methodology, the models to be estimated, and the data. Section 4 presents the empirical results of how banking crises affect the unemployment rate and labor force participation rate. Section 5 extends this analysis by taking a closer look at whether employment protection legislation matters when it comes the unemployment position of the various age groups. Section 6 concludes this paper and put the findings in perspective.

\section{The labor market impact of banking crises in theory and practice}

\section{The impact of a banking crisis}

Banking crises are frequent events around the world and display similar patterns (Kroszner et al., 2007; Reinhart and Rogoff, 2009a, 2009b). Laeven (2011) observes that their causes lie in some combination of unsustainable macroeconomic policies, market failures, regulatory distortions, and/or government interference in the allocation of capital. They occur in both developed and developing countries, although their frequency is higher in developing countries where institutions concerning regulation, accountability and oversight are less developed than in high income countries. However, in developed countries, the impact of banking crises may be far larger because of the interconnectedness and centrality of banks in these societies (Battiston et al., 2016). Banking crises often originate from bank runs (Claessens and Kose, 2013), such as that experienced by Northern Rock in the UK, or more often from a meltdown of asset bubbles, predominantly in real estate (Claessens et al., 2009). As a consequence, banking crises are often found at the center of financial crises, although they often coincide with other financial crises, such as collapses in asset prices, currency crises, and sovereign debt crises (Laeven, 2011).

The impact of a banking crisis tends to be protracted and difficult to deal with using conventional macroeconomic policy instruments. A fullblown banking crisis typically leads to a so-called credit crunch - a severe reduction in the availability of credit - which in turn leads to either bankruptcies or higher interest rates with negative repercussions for investment and consumption spending (Eggertsson and Krugman, 2012; Romer and Romer, 2018). A second transmission channel can be traced to debt overhang - high debt positions with reduced assets of consumers, firms, and governments - that is associated with the aftermath of a banking crisis (Mian et al., 2014; Reinhart et al., 2012). Alleviating the macroeconomic consequences of a banking crisis is also difficult because monetary policy often has lost its effectiveness when dealing with a large-scale crisis. Falling investment and consumption spending are hard to correct when consumer or investor confidence is low, monetary authorities are preoccupied with saving financial institutions in their role as lender of last resort, or, as in the case of the Great Recession, interest rates are approaching the zero bound and government spending is a last resort for stimulating an economy.

The externalities of a banking crisis can be large, as a crisis is not restricted to banks or financial institutions, but recessions can spill over to other sectors of the economy and the lives of people (Antonova et al., 2017; Karanikolos et al., 2013). Given the special role that banks play in the allocation of funds in the economy, banking crises have the potential of inflicting serious damage to the economy, resulting in fiscal outlays to resolve any financial distress, collapses in output and increases in unemployment. Laeven and Valencia (2013) estimate that fiscal costs, net of recoveries, associated with banking crises are about 6.8 percent of GDP on average. However, there have been historic examples, such as Chile and Argentina in the early 1980s, Indonesia in the later 1990s, and Iceland and Ireland in 2008, where this has been over 40 percent of GDP. Laeven and Valencia (2013) also estimate that output losses following a typical banking crisis average approximately 
37 percent of potential output and around 33.7 percent of GDP. However, in some cases such as Ireland and Latvia in 2008 losses in output were equivalent to more than 100 percent of potential GDP.

The labor market is a central domain within the economy where the consequences of a banking crisis can become visible in terms of unemployment rates and the duration of unemployment. Reinhart and Rogoff, 2009a, 2009b, who compare the employment performance of countries in the aftermath of a number of severe banking crises, show that on average these severe banking crises were followed by a 7 percentage point rise in the unemployment rate and it took on average 4.8 years before unemployment even started to fall. However, whilst these aggregate data clearly show the negative impact of financial crises in general and banking crises in particular on economic performance and unemployment, they tell us little about the relative fortunes of different age groups.

Previous studies have shown that business cycles tend to impact on younger workers, those aged below 25 years, more than for workers between 25 and 54 (Keeley and Love, 2010). Bruno et al. (2017) examine how systemic banking crises affect youth unemployment in the short and the long run for a panel of OECD countries for the period 1981-2009. They demonstrate that younger workers (15-24 years) are affected far more by a banking crisis than the average worker, both in the short-run and the long-run. Unfortunately, neither of these studies examine the impact on other age groups. In their analysis of the impact of the Great Recession Cho and Newhouse (2013) do explore the ways in which this crisis affected different groups of workers for a set of middle-income countries or countries in transition. They found that young men in particular were hit heavily by the crisis. However, in their study of the effects of the Great Recession on European countries Groot et al (2012) find that the ratio between youth unemployment and adult unemployment during the recession was relatively constant. They suggest that this is due to a possible substitution effect resulting in reduced effects of the crisis for older workers at the cost of the young. Whilst these more age-disaggregated analyses are useful in highlighting the potential differential effect of banking crises on different age groups they are limited by the fact that they focus solely on the Great Recession. To extrapolate lessons from one large crisis, e.g. the Great Recession, to banking crises in general is difficult as although this crisis shared many features with other financial crises it also had some specific causes and consequences (Claessens, Kose, and Terrones, 2010). To redress both these issues we use data on 41 banking crises in 38 developed countries between 1990 and 2014, to examine how banking crises affect the labor market position of workers from five different age groups, including those aged 65 years and older.

An additional issue when looking at the effects of a banking crisis for different age groups of workers is the possibility that cohort sizes of the population might affect labor market outcomes, e.g., in measuring the long-run effects of adverse unemployment conditions during employment conditions of young workers. Kawaguchi and Murao (2014) point out that the effect of cohort size on labor force status might create serial correlation of cohort specific outcomes of time. In the literature there is some ambiguity about the direction of this effect on labor force status (Garloff et al., 2013; Shimer, 2001; Korenman and Neumark, 2000). Garloff et al. (2013) note that decreasing cohort sizes, notably amongst younger cohorts, may reduce unemployment rates in this age group due to less competition among the workforce. Alternatively, they could increase unemployment if companies reduce jobs disproportionately amongst that cohort. In order to ensure that our results on labor market outcomes of different age groups are not driven by cohort effects due to sizable or small cohorts entering or exiting employment or the labor market we control for this potential channel in our analyses.

\section{Employment protection}

An important issue when discussing the consequences of banking crises is whether and how firms and welfare states can protect workers from unemployment risks. The early consensus on this issue was summarized by Mortensen and Pissarides (1999: p.1172), who state that "large differences in unemployment rates observed in industrialized countries can be attributed to a large extent to differences in policy towards employment protection legislation (which increases the duration of unemployment and reduces the flow into unemployment) and the generosity of the welfare state (which reduces job creation)". However, the analysis of how employment protection legislation (EPL) affects labor market outcomes when an economy is affected by a financial crisis is an under-researched topic (an exception being BernalVerdugo et al. (2013)). In the present paper, we offer some evidence on whether an employment protection regime (high vs. low) matters when a banking crisis occurs. A priori, one would expect that a high EPL regime would be associated with less severe unemployment effects in the short run following a crisis, but such a regime may impose higher costs on firms which in turn lead to lower hiring rates and a longer unemployment duration in the medium or long run compared to a low EPL regime. ${ }^{1}$ As Blanchard et al. (2014) argue, the net effect of EPL may be either positive or negative as the cost of laying off fewer workers could be that the duration of unemployment will be longer. Indeed Groot et al. (2011) find that, in their analyses of the impact of the Great Recession on European economies, employment protection and strong trade unions are more likely to protect employment in the short run but they make employers more reluctant to hire in the long run. However, it is also important to consider how these effects might be different for different age groups. As Bennett and Möhring (2015) note, although EPL should be 'age blind', in many countries it is implicitly biased towards older workers as the level of legal protection depends on tenure. As older workers have had greater opportunities to establish longer tenure and, in most cases, higher pay, this would incur higher severance payments if they were made redundant. This would therefore make it more expensive for organizations to dismiss these workers (Chéron et al., 2011). From this perspective, stricter EPL has a positive impact on older workers by increasing job security and reducing the likelihood of involuntary labor market exit. Based on the foregoing evidence one would hypothesize that younger workers will be more affected by in the short run as they are traditionally the ones with less experience and fewer rights, and that this particular impact of a banking crisis will be stronger in countries with low levels of EPL. However, following this we would expect youth unemployment to drop more quickly in those countries with lower EPL, e.g. more flexible labor markets, as companies seek to grow once the initial shock is over. Conversely, we would expect to see lower levels of unemployment for older employees in high EPL countries in the short run, compared to both younger workers in those countries and older workers in low EPL countries. This is would be in line with evidence from Gielen and Tatsiramos (2012) that shows that countries with lower EPL not only have higher dismissal rates for older workers but also greater rates of labor market exit. However, in the medium term we would expect to see this reversed as organizations would be less willing or able to hire older workers.

\section{Data and methods}

Data

Our analysis focuses on a sample of 38 developed countries, which is composed of the 28 European Union member states and all other countries that are classified as "advanced economies" by the IMF (see Appendix A for list of countries). We obtain annual data on the occurrence of a banking crisis for these countries from the Reinhart and

\footnotetext{
${ }^{1}$ Compare the work of Bartelsman et al. (2016) who show how strong employment protection makes economies less resilient and able to adapt. This could make the unemployment impact for each age group greater than it would have been in a low EPL regime.
} 
Rogoff, 2009a, 2009b, 2011 database. We use their "banking crisis" variable, defined as follows: "a banking crisis is marked by two types of events: (1) bank runs that lead to the closure, merging, or takeover by the public sector of one or more financial institutions; (2) if there are no runs, the closure, merging, takeover, or large-scale government assistance of an important financial institution (or group of institutions), that marks the start of a string of similar outcomes for other financial institutions." For countries that are not in the Reinhart-Rogoff database, we supplement their data with the banking crises database of Laeven and Valencia (2013), who identify "systemic banking crises" using the following two conditions: "(1) Significant signs of financial distress in the banking system (as indicated by significant bank runs, losses in the banking system, and/or bank liquidations); (2) Significant banking policy intervention measures in response to significant losses in the banking system." We refer to the original sources for more detail on the banking crises definitions.

Our final sample consists of 41 banking crises in 38 developed countries over the period 1990-2009. Our sample starts in 1990 since that is the first year for which we can obtain unemployment and labor market participation data for different age groups. Our crisis data end in 2009 since that is the most recent year included in the LaevenValencia database and it offers the possibility of tracking the impact of a crisis up to five years after the start of the crisis.

Fig. 1 shows the number of countries experiencing a banking crisis according to these two data sources in each year during our sample period 1990-2009. Two observations stand out. First, in most years in the sample period, only a minority of the countries in our sample experienced a banking crisis. At most 18 out of 38 countries (in 2008 and 2009) were in a banking crisis in any given year. This observation is important since it implies that, for all banking crises in our sample, a decent control sample of countries that were not in a banking crisis is available. Second, of the 41 banking crisis episodes in the individual countries in our sample, only 18 stem from the Great Recession. Most of the other crises in our sample took place in individual countries during the 1990s. Hence, our results will not be primarily driven by the Great Recession and thus they carry more general implications.

We obtain annual country-level data on labor market indicators from the International Labor Organization (ILO) database, including the unemployment rate (i.e., the number of people who are unemployed as a percentage of the total number of employed and unemployed people) and the labor force participation (i.e., the number of people who engage actively in the labor market, either by working or looking for work, as a percentage of the working-age population) for men and women in five

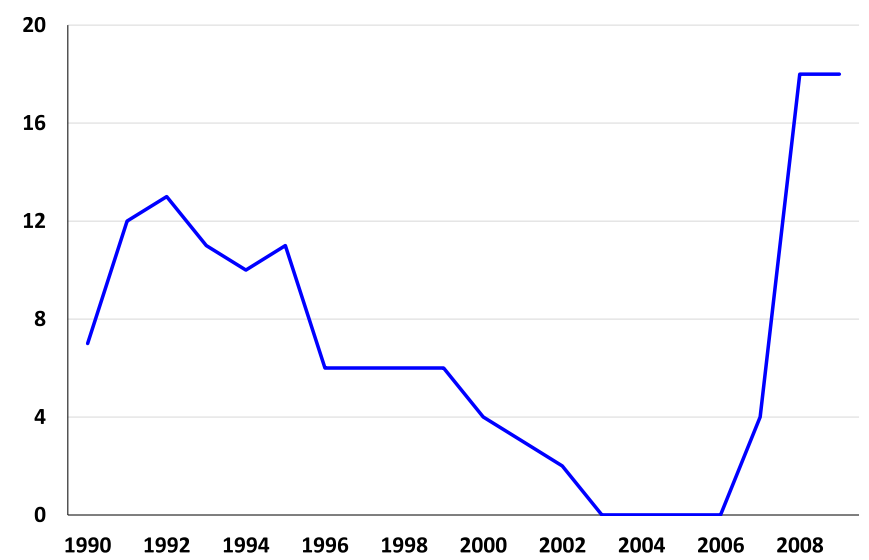

Fig. 1. Number of countries in a banking crisis, 1990-2009. This figure shows the number of countries in our sample of 38 developed countries that experienced a banking crisis in each of the years from 1990 till 2009, based on the databases of Reinhart and Rogoff (2009b, 2011) and Laeven and Valencia (2013). Our crisis data end in 2009 since that is the most recent year included in the Laeven-Valencia database.
Table 1

Summary statistics of unemployment (for different genders and age groups).

\begin{tabular}{|c|c|c|c|c|c|c|}
\hline & Mean & Min & Median & $\operatorname{Max}$ & St. Dev. & \# Obs. \\
\hline \multicolumn{7}{|c|}{ Panel A: Both genders, unemployment rate } \\
\hline Age group 15-24 & 17.27 & 2.59 & 15.31 & 58.29 & 9.35 & 859 \\
\hline Age group 25-34 & 8.48 & 1.56 & 7.56 & 36.06 & 4.69 & 859 \\
\hline Age group $35-54$ & 6.12 & 0.85 & 5.37 & 22.43 & 3.57 & 859 \\
\hline Age group 55-64 & 5.46 & 0.00 & 4.64 & 23.17 & 3.43 & 859 \\
\hline Age group $65+$ & 1.99 & 0.00 & 1.45 & 21.36 & 2.12 & 817 \\
\hline \multicolumn{7}{|c|}{ Panel B: Men only, unemployment rate } \\
\hline Age group 15-24 & 17.14 & 2.73 & 15.60 & 56.19 & 9.05 & 859 \\
\hline Age group 25-34 & 7.95 & 0.53 & 7.18 & 32.85 & 4.51 & 859 \\
\hline Age group 35-54 & 5.84 & 0.53 & 5.04 & 21.47 & 3.69 & 859 \\
\hline Age group 55-64 & 5.86 & 0.00 & 5.01 & 21.10 & 3.67 & 859 \\
\hline Age group $65+$ & 1.89 & 0.00 & 1.32 & 22.50 & 2.25 & 839 \\
\hline \multicolumn{7}{|c|}{ Panel C: Women only, unemployment rate } \\
\hline Age group 15-24 & 17.50 & 2.50 & 14.92 & 63.90 & 10.30 & 859 \\
\hline Age group 25-34 & 9.17 & 1.18 & 7.80 & 39.85 & 5.49 & 859 \\
\hline Age group 35-54 & 6.56 & 0.56 & 5.56 & 26.28 & 3.93 & 859 \\
\hline Age group 55-64 & 4.95 & 0.00 & 4.15 & 25.83 & 3.45 & 859 \\
\hline Age group $65+$ & 2.20 & 0.00 & 1.34 & 40.00 & 3.11 & 835 \\
\hline
\end{tabular}

This table presents summary statistics (the mean, minimum, median, maximum, standard deviation, and the number of country-year observations) of the unemployment rate (the number of people who are unemployed as a percentage of the total number of employed and unemployed people) for five different age groups for both genders (Panel A), men only (Panel B), and women only (Panel C). The sample consists of 38 developed countries over the period 1990-2014.

different age groups $(15-24,25-34,35-54,55-64,65$ and older, see Appendix A for more details). The ILO defines unemployed people as "all people of working age who were: (a) without work during the reference period, i.e. were not in paid employment or self-employment; (b) currently available for work, i.e. were available for paid employment or self-employment during the reference period; and (c) seeking work, i.e. had taken specific steps in a specified recent period to seek paid employment or self-employment." The coverage of the labor force participation data across countries and years is slightly better than the coverage for the unemployment data. For comparability, we use the common sample of country-year observations for which both the unemployment rate and the labor force participation are available (by gender and age group) in all analyses reported in the paper. For both variables, we use data over 1990-2014, such that we can analyze the effects of banking crises on labor market outcomes up to five years after the end of our sample of banking crises over 1990-2009.

Tables 1 and 2 present summary statistics for the labor market variables used in this study for men and women and for the five age groups. Table 1 presents summary statistics for the unemployment rates for both men and women. The unemployment distribution across age groups is quite skewed. On average, the youth unemployment rate (15-24 years) of 17.3 percent is about three times as high as the unemployment rate among older workers (55-64 years) of 5.5 percent. Not surprisingly, there is also substantial variation in unemployment rates across countries and years. For example, the maximum youth unemployment rate in the sample was observed for Greece in 2013, at 58.3 percent, while youth unemployment in Luxembourg in 1991 was only 2.6 percent. Patterns in the mean unemployment rates across age groups are similar for men and women. We note that the number of country-year observations is slightly smaller for the age group 65 and older than for the other age groups.

Summary statistics for the labor force participation rates are displayed in Table 2. They reflect the well-known pattern that labor force participation rates are higher for men than for women at all ages (Grigoli et al., 2018), although the difference is relatively small for the youngest age group (15-24 years).

To examine the differences in the impact of banking crises on labor market outcomes across employment protection regimes, we use data from the OECD-IDB database describing employment protection 
Table 2

Summary statistics of labor force participation (for different genders and age groups).

\begin{tabular}{|c|c|c|c|c|c|c|}
\hline & Mean & Min & Median & Max & St. Dev. & \# Obs. \\
\hline \multicolumn{7}{|c|}{ Panel A: Both genders, labor force participation rate } \\
\hline Age group 15-24 & 48.52 & 24.62 & 47.00 & 76.49 & 13.51 & 859 \\
\hline Age group 25-34 & 83.91 & 70.29 & 84.78 & 93.97 & 4.30 & 859 \\
\hline Age group 35-54 & 83.77 & 64.19 & 84.18 & 94.11 & 5.59 & 859 \\
\hline Age group 55-64 & 49.89 & 17.41 & 49.31 & 88.74 & 14.92 & 859 \\
\hline Age group $65+$ & 8.81 & 0.95 & 6.50 & 39.65 & 7.21 & 817 \\
\hline \multicolumn{7}{|c|}{ Panel B: Men only, labor force participation rate } \\
\hline Age group 15-24 & 51.26 & 23.41 & 50.72 & 80.03 & 13.03 & 859 \\
\hline Age group 25-34 & 92.18 & 80.91 & 92.55 & 97.87 & 2.93 & 859 \\
\hline Age group $35-54$ & 91.88 & 80.48 & 92.12 & 99.02 & 3.21 & 859 \\
\hline Age group 55-64 & 60.65 & 26.70 & 62.29 & 95.86 & 14.13 & 859 \\
\hline Age group $65+$ & 12.59 & 0.64 & 9.72 & 50.34 & 9.70 & 839 \\
\hline \multicolumn{7}{|c|}{ Panel C: Women only, labor force participation rate } \\
\hline Age group 15-24 & 45.66 & 19.45 & 43.87 & 78.07 & 14.39 & 859 \\
\hline Age group 25-34 & 75.47 & 45.84 & 76.76 & 92.92 & 7.87 & 859 \\
\hline Age group 35-54 & 75.63 & 35.97 & 77.10 & 92.55 & 11.07 & 859 \\
\hline Age group 55-64 & 39.87 & 9.21 & 39.03 & 85.29 & 16.84 & 859 \\
\hline Age group $65+$ & 5.72 & 0.27 & 3.60 & 35.82 & 5.62 & 835 \\
\hline
\end{tabular}

This table presents summary statistics (the mean, minimum, median, maximum, standard deviation, and the number of country-year observations) of the labor force participation rate (the number of people who engage actively in the labor market, either by working or looking for work, as a percentage of the working-age population) for five different age groups for both genders (Panel A), men only (Panel B), and women only (Panel C). The sample consists of 38 developed countries over the period 1990-2014.

legislation (EPL) in the OECD as well as some non-OECD countries. The OECD indicators of employment protection are synthetic indicators of the strictness of regulation on dismissals and the use of temporary contracts. $^{2}$ They are compiled from 21 items covering three different aspects of employment protection regulations as they were in force on January 1st of each year. For the purpose of this paper and in light of the country coverage, we use a synthetic indicator ("Employment Protection Regular Contracts" or EPRC) that refers to the strictness of the employment protection for individual dismissals for employees with regular/indefinite contracts covering the years 1985-2013 and it comprises information on eight sub-indicators: (1) notification procedures, (2) delay involved before notice can start, (3) length of notice period at different tenures, (4) severance pay at different tenures, (5) definition of justified or unfair dismissal, (6) length of trial period, (7) compensation following unfair dismissal, and (8) possibility of reinstatement following unfair dismissal. Because some data points were missing for some countries, we categorize each country as belonging either to a high or a low employment protection regime. To that end, we first compute the mean EPRC for each country over the sample period, and then categorize each country as belonging to a low or high protection regime depending on whether the country's mean EPRC is below or above the median of the mean EPRC across all countries in our sample. ${ }^{3}$

\footnotetext{
${ }^{2}$ There are various indicators in use in research (see, e.g. Bernal-Verdugo et al. 2013), but we have used this comprehensive indicator as it based on actual information on labor market institutions and not like some sources, e.g. Fraser Institute, and World Economic Forum, that rely on surveys. As noted by Aleksynska and Cazes (2014) in a comparative report on labor market regulation indicators call for "a cautious use of such indicators for research and policy advice." Comparative research based on different indicators can improve understanding of such institutions.

${ }^{3} \mathrm{~A}$ cautionary note in interpreting these dummy variables capturing the protection regimes is that this dummy variable obscures the fact that many countries are in the middle. Furthermore, the mean computed for each country masks that over the sample period some countries have witnessed changes (albeit that on close inspection of the OECD indicator the values are quite stable
}

\section{Methods}

A main advantage of our approach to examine the labor market effects of banking crises using a large number of crises in a substantial number of countries over a prolonged time period is that we can estimate panel models that effectively represent a "difference-in-differences" estimation in which countries that do not experience a banking crisis are used as a control group for countries that are "treated" by a banking crisis. In particular, we estimate panel models of the following form:

$Y_{c, t}=\alpha_{c}+\alpha_{t}+\beta_{c} t_{c}+\sum_{k=0}^{5} \gamma_{k} B C_{c, t-k}+\sum \theta_{c} X_{c}+\epsilon_{c, t}$,

where $Y_{c, t}$ is the labor market variable of interest (unemployment or labor force participation for different genders and age groups) for country $c$ in year $t ; \alpha_{c}$ and $\alpha_{t}$ represent country and year fixed effects, respectively; $t_{c}$ denotes a country-specific time trend; $B C_{c, t-k}$ is a dummy (indicator) variable indicating whether or not year $t-k$ was the starting year of one of the 41 banking crises in our sample for country $c$, based on the databases of Laeven and Valencia, 2013; Reinhart and Rogoff, 2009a, 2009b, 2011; and $X_{c}$ denotes country-specific control variables in various specifications, discussed in more detail below). In our empirical implementation, we set the maximum $k$ equal to 5 , so that we include the banking crisis dummy both contemporaneously and with lags up to and including five years. This choice is motivated by Reinhart and Rogoff's (2009a) finding that the unemployment effects of banking crises peak after 4.8 years. ${ }^{4}$

The coefficients $\gamma_{0}$ through $\gamma_{5}$ in panel regression (1) capture the contemporaneous and up to five-year lagged impact of a banking crisis on the labor market variable of interest and can be interpreted as "difference-in-differences" estimates of the effects of banking crises that implicitly take all countries not in a banking crisis as a control group. The country fixed effects and year fixed effects absorb any time-invariant differences across countries in the variable of interest as well as any global time variation in the variable of interest. This approach is common in the prior literature (Bertrand and Mullainathan, 2003). In addition, to account for any country-specific secular trends over time in the variable of interest, all our panel models include a country-specific time trend. ${ }^{5}$ To take care that the results are not driven by the size of cohort effects leaving and entering the labor market, we include the share of all cohorts of the respective age groups in the population as extra control variables in all of our analyses. In addition to these controls, in robustness tests we also include variables for the country's political system (Worldbank, 2017), the occurrence of natural disasters (EM-DAT, 2019), and the occurrence of violence or war (Center for Systemic Peace, 2019) in each country-year to make sure that a banking crisis is not mistaken for another (non-economic) crisis or event.

The key identifying assumption underlying this "difference-in-

\section{(footnote continued)}

over the sample period).

${ }^{4}$ Given the sample period of 2009-2014, using more lags would come at the expense of losing a relative large fraction of our data in the panel regressions, although we explore the effects of banking crises on unemployment up to ten years after the start of the banking crises in our descriptive analyses below.

${ }^{5}$ We note that including a country-specific time trend in our panel model regressions likely renders our estimated $\gamma_{k}(k=1, . ., 5)$ to be conservative estimates of the impact of banking crises on labor market outcomes, since this time trend may pick up some of the effects of the Great Recession at the end of our sample period. Indeed, our main results are stronger both statistically and economically when we do not include a country-specific time trend, but this specification also generates results for labor force participation that immediately increases quite strongly for middle aged workers once a banking crisis occurs whereas labor market research on labor force participation suggests that participation only increases once the economic conditions improve (cf Van Zandweghe, 2012; Krueger, 2017). 
differences" interpretation is that banking crises are exogenous to labor market outcomes. Since the roots of banking crises lie in the financial sector and since they pre-date economic downturns (Dell'Ariccia et al., 2008), this assumption seems reasonable. Statistical significance of the estimates of $\gamma_{k}(k=1, . ., 5)$ is assessed based on standard errors clustered by country (Petersen, 2009). We carry out a host of robustness relative to the baseline model specification in Eq. (1) (discussed in more detail in section 4).

To study the effects of employment protection legislation (EPL) on the labor market impact of banking crises for the various age groups, we estimate similar panel regressions as in Eq. (1) but allow the coefficients $\gamma_{k}(k=1, . ., 5)$ to vary across two groups of countries based on the EPL. In particular, we distinguish between countries with low employment protection and with high employment protection based on the median value across countries of our EPL variable ("Employment Protection Regular Contracts" or EPRC) averaged over all the years in our sample for a particular country. The differential effects of banking crises on unemployment in low and high employment protection countries can be estimated by interacting the banking crisis dummy variable $B C_{c, t-k}$ in Eq. (1) with a dummy variable for low vs. high EPL countries, as follows:

$$
\begin{aligned}
Y_{c, t}= & \alpha_{c}+\alpha_{t}+\beta_{c} t_{c}+\sum_{k=0}^{5} \gamma_{k}^{\text {Low } B C_{c, t-k} \times E P L_{c}^{\text {Low }}} \\
& +\sum_{k=0}^{5} \gamma_{k}^{H i g h} B C_{c, t-k} \times\left(1-E P L_{c}^{\text {Low }}\right)+\sum \theta_{c} X_{c}+\epsilon_{c, t},
\end{aligned}
$$

where $E P L_{c}^{\text {Low }}$ is a dummy variable indicating countries in the low employment protection regime. The estimates of $\gamma_{k}^{\text {Low }}$ and $\gamma_{k}^{\text {High }}$ $(k=1, . ., 5)$ give the estimated effects of the banking crises at different lags on unemployment in the low and high EPL regimes, respectively. This approach allows for statistical (Lagrange Multiplier) tests on differences in the impact of banking crises on unemployment between countries with low and high employment protection by testing the null hypothesis $H_{0}: \gamma_{k}^{\text {Low }}=\gamma_{k}^{\text {High }}(k=1, . ., 5)$.

\section{Impact of a banking crisis on labor market outcomes}

In this section, we examine the effects of a banking crisis on labor market outcomes in our sample of 38 developed countries over the period 1990-2014. In Section 4.1, we present the results for the unemployment rate for men and women in five different age groups (15-24, 25-34, 35-54, 55-64, 65+). In Section 4.2, we present the results for the labor force participation.

\section{Unemployment rate}

We start out with a graphical analysis of the dynamics of unemployment around the start of the 41 banking crises in our sample. Fig. 2 depicts the results of a simple "event study" in which the average unemployment rate for countries that experience a banking crisis is plotted from two years before and up to ten years after the start of the crisis (which is denoted as year 0 in the graph). The different lines show the dynamics of unemployment for the five age groups.

A number of interesting observations arise from the graph. First, the unemployment rate is flat on average in the two years before the start of a banking crisis, lending credibility to our identifying assumption that banking crises are exogenous to labor market outcomes. Second, for all age groups except $65+$, unemployment starts to pick up already in the starting year of the banking crisis. Third, unemployment continues to increase for these four age groups in the subsequent five years, peaking at four or five years after the start of a banking crisis. Fourth, unemployment does recover in the longer run, but even ten years after the start of a banking crisis unemployment has not returned to pre-crisis levels. Fifth, the unemployment impact of a banking crisis is more severe for the younger age groups. In particular, young workers (aged

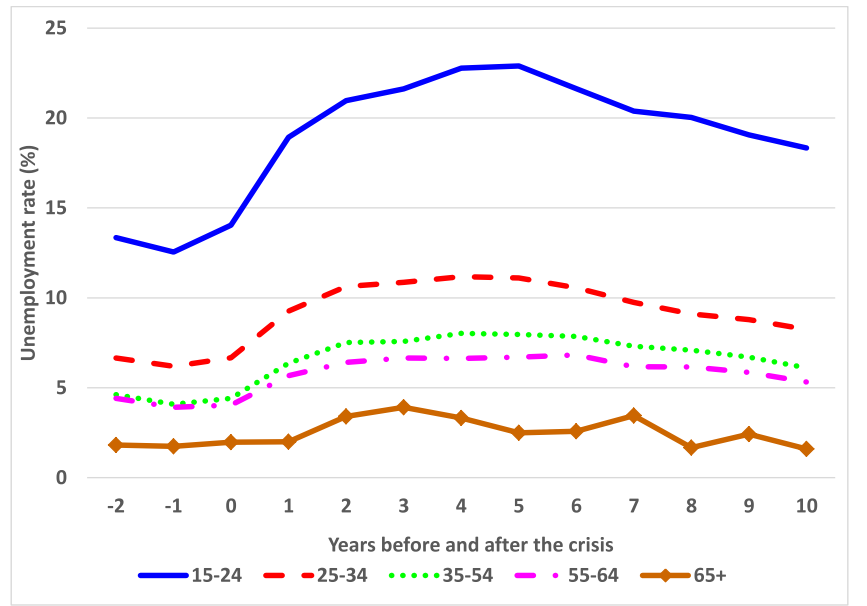

Fig. 2. Dynamics of unemployment in different age groups around banking crises. This figure shows the dynamics of the average unemployment rate for five different age groups (both genders; in \%) in an event window from two years before till ten years after the start of a banking crisis (which is denoted as year 0 ). The sample consists of 38 developed countries over the period 1990-2014.

15-24) not only face the highest pre-crisis unemployment rate (at around 13 percent) but also experience by far the greatest increase in unemployment following a banking crisis, up to more than 22 percent five years after the start of a crisis. After ten years, youth unemployment levels are still elevated compared to pre-crisis levels, at around 18 percent. $^{6}$

The patterns in Fig. 2 provide some initial evidence that the unemployment of banking crises is severe and long-lasting, especially for younger workers. However, these patterns do not properly account for the unemployment effects for a control group of countries not in a banking crisis and could in part be explained by global business cycle effects that happen to be correlated with the local occurrence of banking crises. Also, since the figure is based on all countries in a given event year for which data on the unemployment rate for different age groups are available (and is thus not restricted to countries for which unemployment rates are available in each year in the 13-year event window - as that would lead to discarding many observations), the pattern could also in part due to differences in the level of unemployment across countries. As discussed previously, a proper analysis of the unemployment impact of banking crises therefore requires the estimation of panels models expressed in Eq. (1) that include a control group as well as country and year fixed effects. To be conservative, these models further include a country-specific time trend. To ensure that this parsimonious model offers robust insights we also carried out alternative models to be sure that the underlying idea of this event study analysis is valid, viz. that the labor market dynamics of countries hit by a banking crisis can be compared to those that are not hit by a crisis. For matters of brevity they are not presented here, but these robustness tests ${ }^{7}$ do not change the general conclusions in

\footnotetext{
${ }^{6}$ To assess to what extent our results are driven by the Great Recession (during which 18 out of the 38 countries in our sample were in a banking crisis), in unreported analyses we recreate Fig. 2 when ending our sample period in 2007. The resulting graph is very similar.

${ }^{7}$ These alternative models include: population weighted estimates; models estimated separately for small and for large countries; models with leads of the banking crisis dummy; models with additional control variables for political system, natural disasters, and violence; models with a contemporaneous (Year 0 ) as well as up to five lags after a recession dummy (defined as country-years with negative GDP growth) or GDP growth itself; models with sample 1990-2007 excluding the Great Recession; and models excluding the countryspecific time trend. The results of these robustness tests are available from the
} 
this paper. ${ }^{8}$ We only mention one of the robustness tests that is quite crucial, viz. the assumption that the group of countries not in a crisis is a good comparison group for the countries in a crisis. ${ }^{9}$ To test this possibility we have included dummies of leads of banking crises (i.e., whether or not a crisis will hit in one year, in two years, in three years). The main idea is that when these leads are close to zero, this indicates that the control group is valid since the parallel trend assumption of the difference-in-difference is satisfied (that is, there are no systematic differences between treatment and control group before a banking crisis). Model runs with these leads show that coefficients are indeed close to zero and rarely statistically significant.

Table 3 presents the results of panel models to estimate the impact of banking crises on the unemployment rate of the five different age groups, for men and women combined (Panel A), men only (Panel B), and women only (Panel C). The table shows the coefficients on the contemporaneous (Year 0) banking crisis dummy as well as up to five lags of the banking crisis dummy (Years 1 through 5). ${ }^{10}$ Table 3 also reports both the overall $R^{2}$ and the within $R^{2}$ (that indicates the fraction of variation in the dependent variable after removing country and year fixed effects that can be explained by the independent variables) as well as the number of country-year observations in the panel. Standard errors are clustered by country.

The impact of banking crises on the unemployment rate is statistically and economically significant for both men and women in Table 3, but certainly not for all age groups, and when the banking crisis becomes apparent (Year 0) one can detect no significant impact. It is particularly the young and middle aged who are hit by the negative consequences of a banking crisis, but this impact for all age groups only becomes visible after some years. To illustrate the impact for men, one year after the banking crisis the unemployment for young men (15-24) immediately rises by 2.5 percentage points, increasing even further in year 2 to 4.2 percentages points. From year 3 onwards, the impact decreases, although by year 5 the banking crisis still leaves its mark on youth unemployment as this rate is 2.3 percentage points higher than it would have been without a banking crisis.

This type of impact for the young is consistent with prior studies (Bruno et al., 2017; Scarpetta et al., 2010; Tanveer Choudhry et al., 2012). The greater impact on their unemployment rate could be due to the fact that their labor contracts generally tend to be of a temporary nature and dismissing the young in the event of a crisis imposes fewer costs on the employer than dismissing tenured and older workers.

However, at higher ages the unemployment impact of banking crises is less well-examined. One can see in Table 3 that men above the age of 25 experience the consequences of a crisis two years after they occur. The impact is, however, far smaller than that observed for the young. For instance, the unemployment rate of older men (55-64 years) only started to increase in year 2 by 1.9 percentage points, which is more than half the impact for the young; and the same applies to some degree for later years. The absence of an effect for both men and women 65 years and older stands to reason, as in most countries one cannot

\section{(footnote continued)}

authors upon request.

${ }^{8}$ We note, however, that our results are considerably weaker when adding lags of a recession dummy or of GDP growth itself, suggesting that the labor market effects of banking crises stem from their impact on overall economic conditions. Banking crises differ from regular recessions in that recessions associated with banking crises tend to be deeper than other recessions (Claessens et al., 2009).

${ }^{9}$ We thank one of the reviewers for suggesting this test.

${ }^{10}$ We restrict the number of lags in the panel models to five - as opposed to ten lags in the event study in Fig. 2 - since the use of ten lags would lead to discarding a considerable fraction of the data in light of the relatively short sample period for the banking crises data of 1990-2009. Fig. 2 suggests that five-year lags suffice to capture the maximum impact of the banking crisis on unemployment. claim any unemployment benefits at these ages and it is only by the registering process of labor force surveys that people can be defined as unemployed.

For women, the unemployment impact of banking crises tends to be more muted than for men. Young women experience a significant increase in the unemployment rate of up to 2.6 percentage points two years after the start of a crisis, reverting back to 2.2 percentage points in year 5 . The impact of the crisis on the unemployment rates for women is also noticeable for the age brackets $35-54$ years and statistically significant in years 2 and 5 . For all women below the age of 55, we find that by year 5 unemployment has risen significant.

The overall $R^{2}$ and within $R^{2}$ of the panel models in Table 3 indicate that, while the country and year fixed effects account for the vast majority of the explanatory power of the panel models, the six banking crisis dummies, relative cohort controls, and the time trend contribute up to 8 percent of the explanatory power for regular working ages among men and around 7 percent for women ( 3 percent for women of 55-64 years), for the 65 years and older the explanatory power drops to around 2 to 3 percent.

Overall, Table 3 indicates that banking crises are associated with large and long-lasting negative unemployment effects for women and especially for men, and most notably (but not exclusively) for young workers. We note that, although many of the coefficients in Table 3 are both economically and statistically significant, there is reason to believe that they potentially underestimate the actual effects of banking crises on unemployment, since the country and time fixed effects and countryspecific time trend may all to some extent absorb some of the "real" effects of banking crises. As a result, the 10 percentage points unemployment effect for young men and women observed in Fig. 2 shrinks to an estimate effect of only up to around 3.5 percentage points in Panel A of Table 3.

\section{Labor force participation}

Table 4 presents the results of similar panel models as in Table 3, but with the labor force participation rate for different age groups as dependent variable. Overall, the results are much weaker. The short run impact of banking crises on the labor force participation rate (see Table 4) is negligible for all age groups. The absence of labor force participation effects, together with the previously noted unemployment impact of banking crises, suggests that unemployment developments are primarily the result of employment developments as opposed to developments in people's active engagement in the labor market by looking for work. In other words, banking crises cause firms and governments to decrease their labor demand and do not result in an increase in labor supply. This insight deepens our understanding of the labor market impact of banking crises and - as far as we know - has not been documented before.

Still, there are some sizeable and interesting effects to be seen in Table 4. If we restrict our attention to sizeable effects at the 5 percent significance level, we note two important effects. First, one can detect amongst older men (55-64 years) a "discouraged worker" effect, visible in year 4: illustrated by a decrease in labor force participation of 1.2 percentage points in year 4 . These effects may arise from the employee themselves, being discouraged by their lack of labor market prospects in times of crisis or perhaps triggered by well-intended but badly designed social insurance programs (Inderbitzin et al., 2016). But it may also be a choice that has been induced from the employer side. Employers may want try to "lay off" workers by using early retirement programs (Van Dalen and Henkens, 2013), thereby softening the income blow for older workers if they had to dismiss them and let their older employees use unemployment insurance programs.

A second and novel effect to be noted from Table 4 is the increase in labor force participation of women aged 65 years and older (and to a limited extent of men). Between years 2 and 4 one can see an increase in participation amongst this group of $0.5-0.6$ percentage points. These 
Table 3

Panel models of the impact of banking crises on unemployment (for different genders and age groups).

\begin{tabular}{|c|c|c|c|c|c|c|c|c|c|}
\hline & Year 0 & Year 1 & Year 2 & Year 3 & Year 4 & Year 5 & $\mathrm{R}^{2}$ & Within $\mathrm{R}^{2}$ & \# Obs. \\
\hline \multicolumn{10}{|l|}{ Panel A: Both genders } \\
\hline Unemployment rate (15-24) & 0.857 & $2.165^{*}$ & $3.338^{* *}$ & $2.837 * *$ & $2.322^{*}$ & $2.471^{* * *}$ & 0.858 & 0.080 & 660 \\
\hline Unemployment rate (25-34) & 0.203 & 0.974 & $1.913^{* *}$ & $1.369^{*}$ & $1.188^{*}$ & $1.369^{* * *}$ & 0.846 & 0.084 & 660 \\
\hline Unemployment rate (35-54) & 0.376 & 0.900 & $1.602^{* * *}$ & $0.850^{*}$ & 0.747 & $0.858^{* * *}$ & 0.846 & 0.075 & 660 \\
\hline Unemployment rate (55-64) & -0.057 & 0.435 & $1.374^{* *}$ & 0.906 & 0.577 & $0.887^{* *}$ & 0.818 & 0.065 & 660 \\
\hline Unemployment rate $(65+)$ & -0.224 & -0.544 & 0.216 & 0.281 & -0.004 & -0.114 & 0.636 & 0.018 & 626 \\
\hline \multicolumn{10}{|l|}{ Panel B: Men only } \\
\hline Unemployment rate (15-24) & 0.982 & $2.494 *$ & $4.167^{* *}$ & $3.582^{* *}$ & $2.785^{* *}$ & $2.274^{* * *}$ & 0.814 & 0.085 & 660 \\
\hline Unemployment rate (25-34) & 0.287 & 1.106 & $2.273^{* *}$ & $1.871 * *$ & $1.506^{* *}$ & $1.390 * * *$ & 0.789 & 0.088 & 660 \\
\hline Unemployment rate (35-54) & 0.462 & $1.020^{*}$ & $1.951^{* * *}$ & $1.222^{* *}$ & 0.820 & $1.074^{* * *}$ & 0.821 & 0.076 & 660 \\
\hline Unemployment rate (55-64) & 0.030 & 0.792 & $1.904 * * *$ & $1.275^{*}$ & 0.878 & $1.207^{* * *}$ & 0.793 & 0.080 & 660 \\
\hline Unemployment rate $(65+)$ & 0.686 & -0.404 & -0.186 & 0.212 & 0.058 & -0.333 & 0.515 & 0.024 & 645 \\
\hline \multicolumn{10}{|l|}{ Panel C: Women only } \\
\hline Unemployment rate (15-24) & 0.672 & 1.747 & $2.561^{*}$ & 2.004 & 1.678 & $2.147^{* *}$ & 0.889 & 0.066 & 660 \\
\hline Unemployment rate (25-34) & 0.052 & 0.747 & $1.412^{*}$ & 0.666 & 0.747 & $1.293^{* * *}$ & 0.898 & 0.073 & 660 \\
\hline Unemployment rate (35-54) & 0.271 & 0.752 & $1.143^{* *}$ & 0.415 & 0.589 & $0.598^{*}$ & 0.885 & 0.074 & 660 \\
\hline Unemployment rate (55-64) & -0.038 & 0.044 & 0.677 & 0.467 & 0.134 & 0.529 & 0.808 & 0.034 & 660 \\
\hline Unemployment rate $(65+)$ & -1.091 & -0.551 & 0.765 & -0.394 & 0.611 & 0.031 & 0.495 & 0.033 & 641 \\
\hline
\end{tabular}

This table present the results of panel models to estimate the effect of the start of a banking crisis on unemployment in the same year (Year 0) and in the five subsequent years (Year 1 through Year 5). The dependent variable is the unemployment rate (the number of people who are unemployed as a percentage of the total number of employed and unemployed people) for five different age groups for both genders (Panel A), men only (Panel B), and women only (Panel C). The independent variable is a dummy variable indicating the starting year of a banking crisis that is included both contemporaneously (Year 0) and up to and including five lags (Year 1 through Year 5). All panel models include country and year fixed effects as well as a country-specific time trend and control variables for relative cohort size (not reported in the table). The final three columns report the overall $R^{2}$, the within $R^{2}$, and the number of country-year observations included in the panel model. The table reports the coefficients and their significance $(* * * * *$, and * indicate significance at the $1 \%, 5 \%$, and $10 \%$ level, using standard errors clustered by country). The sample consists of 38 developed countries over the period 1990-2014.

Table 4

Panel models of the impact of banking crises on labor force participation (for different genders and age groups).

\begin{tabular}{|c|c|c|c|c|c|c|c|c|c|}
\hline & Year 0 & Year 1 & Year 2 & Year 3 & Year 4 & Year 5 & $\mathrm{R}^{2}$ & Within $\mathrm{R}^{2}$ & \# Obs. \\
\hline \multicolumn{10}{|l|}{ Panel A: Both genders } \\
\hline Labor force participation rate (15-24) & 0.200 & -0.078 & -1.088 & -0.703 & -0.810 & -0.312 & 0.975 & 0.026 & 660 \\
\hline Labor force participation rate (25-34) & 0.327 & 0.446 & 0.012 & 0.273 & -0.055 & -0.052 & 0.952 & 0.037 & 660 \\
\hline Labor force participation rate (35-54) & 0.046 & 0.189 & 0.314 & 0.389 & 0.324 & 0.116 & 0.982 & 0.047 & 660 \\
\hline Labor force participation rate (55-64) & 0.371 & 0.568 & 0.095 & -0.447 & $-0.839^{*}$ & -0.516 & 0.989 & 0.038 & 660 \\
\hline Labor force participation rate $(65+)$ & 0.057 & 0.229 & $0.616^{*}$ & $0.637 * *$ & $0.592 * *$ & -0.148 & 0.976 & 0.066 & 626 \\
\hline \multicolumn{10}{|l|}{ Panel B: Men only } \\
\hline Labor force participation rate (15-24) & -0.147 & -0.417 & -0.900 & -0.447 & -0.616 & -0.215 & 0.970 & 0.024 & 660 \\
\hline Labor force participation rate (25-34) & 0.361 & 0.330 & -0.147 & 0.215 & 0.059 & -0.068 & 0.919 & 0.025 & 660 \\
\hline Labor force participation rate (35-54) & 0.115 & 0.217 & 0.334 & 0.307 & 0.278 & -0.108 & 0.957 & 0.037 & 660 \\
\hline Labor force participation rate (55-64) & -0.108 & 0.322 & -0.502 & -0.718 & $-1.221 * *$ & -0.830 & 0.985 & 0.059 & 660 \\
\hline Labor force participation rate $(65+)$ & -0.295 & 0.115 & 0.556 & 0.773 & $0.640^{*}$ & -0.449 & 0.977 & 0.074 & 645 \\
\hline \multicolumn{10}{|l|}{ Panel C: Women only } \\
\hline Labor force participation rate (15-24) & 0.560 & 0.271 & $-1.285^{*}$ & -0.973 & -1.012 & -0.413 & 0.975 & 0.030 & 660 \\
\hline Labor force participation rate (25-34) & 0.333 & 0.602 & 0.225 & 0.372 & -0.140 & -0.005 & 0.969 & 0.044 & 660 \\
\hline Labor force participation rate (35-54) & -0.033 & 0.141 & 0.267 & 0.453 & 0.356 & 0.323 & 0.992 & 0.046 & 660 \\
\hline Labor force participation rate (55-64) & 0.742 & 0.705 & 0.579 & -0.244 & -0.497 & -0.215 & 0.990 & 0.020 & 660 \\
\hline Labor force participation rate $(65+)$ & 0.331 & 0.442 & $0.632^{* *}$ & $0.540 *$ & $0.541 *$ & -0.045 & 0.969 & 0.048 & 641 \\
\hline
\end{tabular}

This table present the results of panel models to estimate the effect of the start of a banking crisis on labor force participation in the same year (Year 0 ) and in the five subsequent years (Year 1 through Year 5). The dependent variable is the labor force participation rate (the number of people who are unemployed as a percentage of the total number of employed and unemployed people) for five different age groups for both genders (Panel A), men only (Panel B), and women only (Panel C). The independent variable is a dummy variable indicating the starting year of a banking crisis that is included both contemporaneously (Year 0) and up to and including five lags (Year 1 through Year 5). All panel models include country and year fixed effects as well as a country-specific time trend and control variables for relative cohort size (not reported in the table). The final three columns report the overall $R^{2}$, the within $R^{2}$, and the number of country-year observations included in the panel model. The table reports the coefficients and their significance $(* * * * *$, and * indicate significance at the $1 \%, 5 \%$, and $10 \%$ level, using standard errors clustered by country). The sample consists of 38 developed countries over the period 1990-2014.

effects may not seem large in an absolute sense, but considering the low unconditional mean labor force participation for women aged $65+$ age of only 5.7 percent (see Table 2), these effects are relatively large for the age group itself (around 10 percent in the medium run relative to the unconditional mean). The fact that this age group, normally seen as pensioners, increases their participation on the labor market after a banking crisis may have a myriad of causes. The relatively recent turn in increasing labor force participation of older workers (55-64 years) can be ruled out as a major cause as this study focuses on banking crises in general and not just the most recent crisis. What unites banking crises may very well be the fact they generate uncertainty in financial markets and hence may affect the private assets and compulsory accumulated savings within pension funds or insurance companies. Especially in countries where (private) pension contracts are based on a defined contribution basis, dwindling assets may become directly visible and trigger potential retirees to continue working or perhaps retire and at 
Table 5

Panel models of the impact of banking crises on unemployment: Low vs. high employment protection.

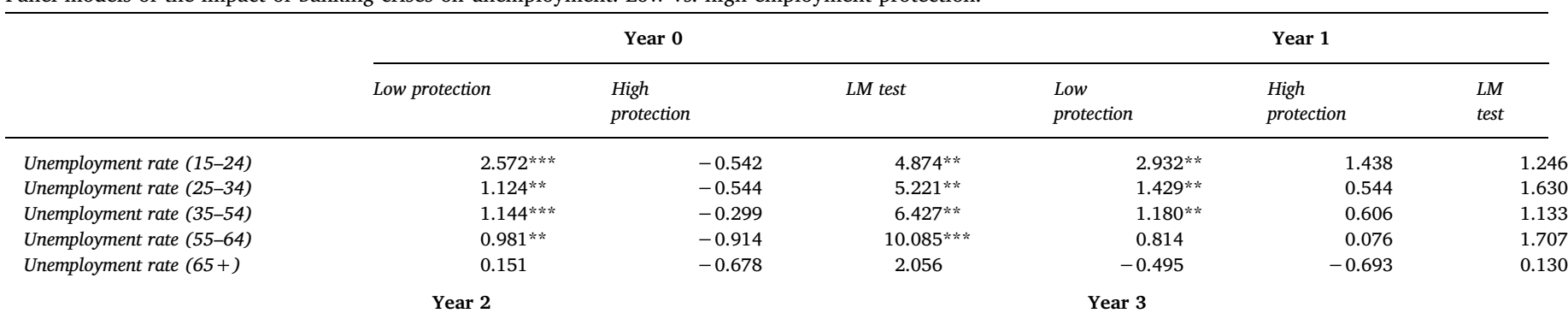

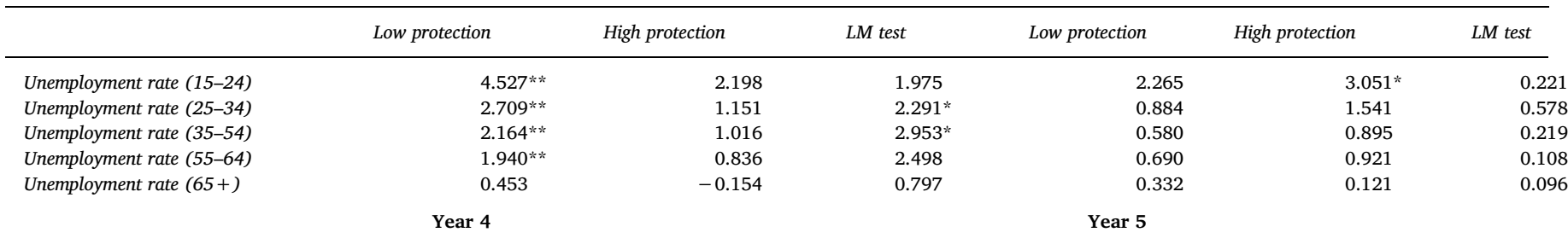

\begin{tabular}{|c|c|c|c|c|c|c|}
\hline & Low protection & High protection & LM test & Low protection & High protection & $L M$ test \\
\hline Unemployment rate (15-24) & 0.970 & $3.333^{*}$ & 2.222 & 0.956 & $2.897 * *$ & 1.640 \\
\hline Unemployment rate (25-34) & 0.880 & $1.471^{*}$ & 0.520 & 0.716 & $1.512^{* *}$ & 1.031 \\
\hline Unemployment rate (35-54) & 0.414 & $1.047^{*}$ & 0.983 & 0.202 & $0.999 * *$ & 1.704 \\
\hline Unemployment rate (55-64) & 0.583 & 0.695 & 0.029 & 0.324 & 0.859 & 0.705 \\
\hline Unemployment rate $(65+)$ & -0.167 & 0.177 & 0.283 & -0.305 & -0.418 & 0.034 \\
\hline
\end{tabular}

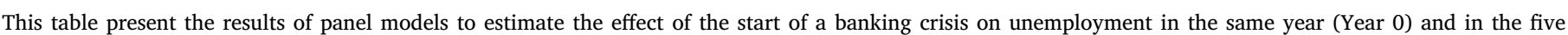

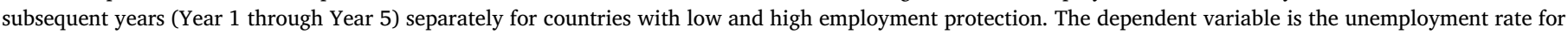

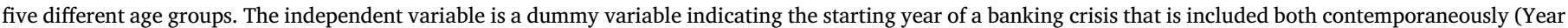

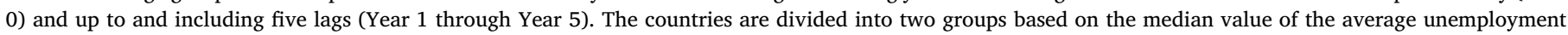

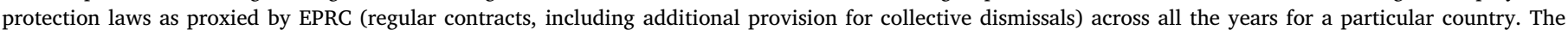

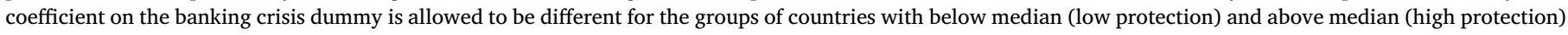

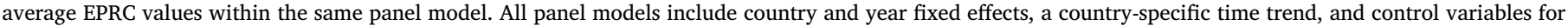

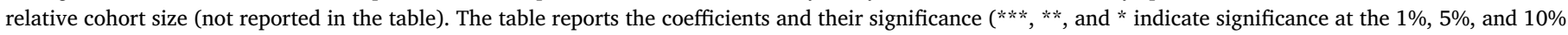

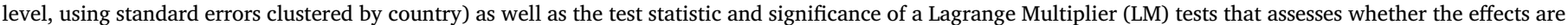
the same across the two groups of countries. The sample consists of 38 developed countries over the period 1990-2014.

the same time keep on working part-time to compensate for the fall in income from assets (Szinovacz et al., 2015).

Taken together, the results in this section indicate that the strong and long-lasting impact of banking crises on unemployment is accompanied by relative minor labor market participation effects, implying that the unemployment effects primarily stem from labor demand forces. In the next section, we address the question whether labor market legislation can help to alleviate the unemployment effects of banking crises.

\section{How effective is employment protection legislation?}

An important topic in labor market policies is whether employment protection legislation (EPL) offers real protection in the short and long run in the face of a crisis. A banking crisis would in that respect put an EPL system sufficiently to the test. In this section, we examine this issue by splitting up the sample according to whether the level of employment protection in a country is above the median value of protection (termed "high protection") or below that value (termed "low protection"). We study how the unemployment rates of the various age groups are affected by the banking crisis in the two employment protection regimes (high vs. low).

Table 5 shows the results of panel models expressed in Eq. (2) in which the coefficients on the different lags of the banking crisis dummy are allowed to be different across both groups of countries. The table contains the coefficient estimates for the contemporaneous as well as five lags of the banking crisis dummy for both regimes separately, as well as the results of a Lagrange Multiplier (LM) test on the significance of the difference in the coefficients across both regimes for all individual lags (Year 0 through 5) separately. We note that the table presents the results of five different panel models (one for each age group, men and women combined) for each of which 12 coefficients are shown (coefficients for Year $0-5$ for High and Low protection countries). $R^{2}$ s are suppressed for space considerations. The results in Table 5 thereby present an overview of the short and medium run impact of banking crises on the unemployment rate for different age groups in the different EPL regimes for workers with regular employment contracts. ${ }^{11}$

The differences in the short run effects across the two regimes are quite striking and in line with expectations: in the low EPL regime, all workers are immediately negatively affected in the year the banking crisis starts (year 0), whereas in high protection regime the unemployment rate of all workers is hardly affected. This applies in a more pronounced manner for years 1 and 2. For example, young workers (15-24) in low EPL countries face a substantial increase in their unemployment rate starting from 2.6 percentage points in year 0

\footnotetext{
${ }^{11}$ To examine whether the estimation results are different for those employees working on the basis of temporary contracts, we also estimate the impact of banking crisis across different EPL regimes with respect to temporary contracts (as approximated by the OECD indicator EPT). The general picture presented in this paper is by and large the same for temporary contracts and is for matters of brevity not presented here (but available upon request for interested readers)
} 
and increasing to 4.5 percentage points in year 2 . These effects are highly statistically significant and considerably stronger than those observed in Table 3 for all countries combined. In contrast, young workers in high EPL countries do not experience a significant increase in their unemployment rate in years 0,1 and 2 . These patterns are similar, though somewhat less pronounced, for the other age groups, consistent with the finding in Table 3 that young workers suffer the most in the wake of banking crises.

However, when we look at the medium run effects of banking crises on workers in the different regimes, a clear pattern emerges. In the low protection regime, the unemployment effects turn out to be temporary, as the coefficients for years 4 to 5 are relatively small and statistically insignificant for all age groups. Hence, employment opportunities recover within several years after the start of a banking crisis. In contrast, in the high protection regime, significant detrimental labor market effects start to materialize three to five years after the start of a banking crisis. In particular, we see that the unemployment rate in years 4 and 5 increase substantially for the young and middle-aged workers. For example, young workers in the high EPL regime face a medium run increase in their unemployment rate of around 3 percentage points, while middle-aged workers (25-34) and (35-54) witness their unemployment deteriorate by 1 to 1.5 percentage points.

This result may seem counterintuitive, but could actually be a sign that low protection regimes are more adaptive and incur the "pain" of a crisis as soon as possible and start restructuring, thereby being able to reap the benefits of this strategy (Bartelsman et al., 2016; Gnocchi et al., 2015; Martin and Scarpetta, 2012). The high protection regime, on the other hand, offers true protection in the short run, but the downside of a high degree of protection may be a lack of resilience and, in case of a deep recession, firms are bound to keeping their workers on the payroll in spite of losses. In the medium run, this strategy may no longer be sustainable, leading firms to downsize or stop hiring regardless and hence the unemployment rate of young and middle aged workers starts to increase. ${ }^{12}$

In sum, the results in Table 5 suggest that while EPL can alleviate the short run adverse labor market consequences of banking crises, imposing strong employment protection can result in less flexible labor markets that seem to be associated with significant economic costs that are born in particular by young workers in the medium and long run.

\section{Conclusion and discussion}

The financial crisis of 2009 has made governments and citizens aware that a banking crisis can have long-lasting negative social consequences (Zingales, 2015). Trying to uncover those consequences and making the social costs of a crisis visible is the main contribution of this paper. By pulling together the data on 38 developed countries that experienced at one time or another a banking crisis it has been possible to examine how younger and older people bear the brunt of such a crisis and how employment protection may soften the blow of a crisis, but in so doing perhaps distort the ability of labor markets to adjust over time (Coile and Levine, 2007; Coile and Levine, 2011).

Our analysis makes four distinctive contributions. First, the few prior studies that examine the labor market consequences of financial crises tend to focus on individual crises and/or individual countries (Scarpetta et al., 2010; Cho and Newhouse, 2013; Axelrad et al., 2018).

\footnotetext{
${ }^{12}$ We note that, while the LM test indicates that the differences in the unemployment effects of banking crises across the low and high protection regimes are statistically significant in years 0 and 2, the differences are not significant at conventional significance levels for the other years. The lack of significance of the LM test statistics for years 3-5 may be due to the increased imprecision of the coefficient estimates, as the impact of banking crises on unemployment rates becomes harder to identify multiple years after the start of the crises, as other forces affecting unemployment likely become relatively more important.
}

An important advantage of our approach to studying a large number of crises in many countries over a prolonged period of time is that we can estimate panel models that effectively represent a "difference-in-differences" estimation in which countries that do not experience a banking crisis are used as a control group for countries that are "treated" by a banking crisis. The key identifying assumption that banking crises are exogenous to labor market outcomes seems reasonable since banking crises originate in the financial sector and pre-date economic downturns (Dell'Ariccia et al., 2008). Furthermore, we control for country and year fixed effects (to account for time-invariant country characteristics as well as global time effects such as common business cycle effects across countries) as well as relative cohort sizes and a country-specific time trend (to account for any secular trends over time that may vary across countries). As a result, our analyses are potentially more powerful in isolating the impact of banking crises on the labor market outcomes for different age groups.

Second, our study is the first to jointly examine the unemployment and the labor market participation effects of banking crises for finegrained age groups. A focus on both variables may help us see how various age groups suffer but also recover over time when a banking crisis occurs. It is to be expected that some workers are laid off during a crisis, thereby affecting the unemployment rate directly. But another adjustment channel could be that a crisis affects the labor force participation of the work force, either in a negative manner - by discouraging workers who thus withdraw from the labor market - or in a positive manner - by encouraging potential workers, who in case of crisis may feel compelled to start searching for paid employment to supplement their pension or household income.

Third, in prior papers that offer an international perspective on the effects of financial crises, the age groups are often broad (Cho and Newhouse, 2013; Bernal-Verdugo et al., 2013) or sometimes the focus is only on young workers (Bruno et al., 2017; Tanveer Choudhry et al., 2012), and labor market research generally neglects the group of men and women that work beyond the age of 65 (Hoynes et al., 2012). In this paper, we offer a more detailed analysis of how various relatively narrow age groups - both men and women and including those above 65 - fare on the labor market in terms of unemployment and labor force participation.

Fourth, this paper yields new insights into the effects of employment protection legislation (EPL) on the labor market impact of financial crises for the various age groups. The extent to which EPL can alleviate the labor market pain of different age groups in the aftermath of (banking) crises is an important policy issue that deserves more research (and replication), certainly as the labor market impact of crises on various age categories will gain attention in aging societies.

Our main results show that, in the aftermath of a banking crisis, the younger workers in particular bear the brunt of a crisis in terms of higher unemployment rate. We find that employment protection is a mixed blessing for young and middle-aged workers. In high protection countries, they initially fare much better compared to their peers in low protection countries, but in the medium run they face considerably larger increases in their unemployment rate.

Across all age groups, we find no immediate impact of banking crises on labor force participation, but we do find significant effects for some age groups in the medium run (after 2-5 years). In particular, male workers in the pre-retirement age group (55-64 years) show some signs of withdrawal from the labor market four years after a crisis This is in line with other studies that show how early retirement programs are a common strategy to downsize firms and deal with older workers (Van Dalen and Henkens, 2013). In contrast, female workers aged 65 years and over increase their labor force participation two to four years after a crisis.

These results on labor force participation are an important complement to the findings of prior studies on unemployment and broaden our understanding of the impact of financial crises on labor market outcomes. Of particular interest are our results on the labor market 
experience of workers aged 65 and older, especially because the current literature generally focuses on standard working age definitions up to 65. Our analysis shows that the impact on the unemployment position of this particular age group of men and women is negligible, whereas the labor force participation of women 65 and older increases by around 0.5 percentage points $2-4$ years after the crisis. This absolute change in labor force participation may not be large, but it is substantial considering that the mean female labor participation rate for those age 65 and older in our sample is only 5.7 percent. Thus, older female workers (65 and older) experience increased pressures from a banking crisis to prolong and increase their participation in the labor market (by almost 10 percent in the medium run relative to the unconditional mean participation).

Needless to say, this study is subject to a number of limitations; limitations that are tightly connected to the highly aggregated nature of the data sets used. First of all, as Claessens and Kose (2013) note banking crises can be particularly challenging to exactly date. The start of a crisis has usually been dated using a qualitative approach on the basis of a combination of events, such as forced closures, mergers, or government takeover of many financial institutions, runs on several banks, or the extension of government assistance to one or more financial institutions. The end of a banking crisis is also difficult to identify, in part since its effects can linger on for some time. Notwithstanding these issues we have employed definitions and data on banking crises from two high-quality, reputable databases which have been used in a number of other studies. However, future research is needed to establish exactly how the labor market effects of banking crises in combination with labor market institutions materialize. What makes these assessments particularly difficult is that aggregate unemployment rates hide the information necessary to make a clear-cut evaluation, and labor market research on how EPL is structured and enacted shows that the devil is often in the details (Blanchard and Landier, 2002; Blanchard et al., 2014; Boeri and Van Ours, 2013; Kahn, 2007; Kahn, 2012; Mortensen and Pissarides, 1999). More detailed insights into the effects of different types of labor market regulation and protection are obvious candidates for future research.

Despite these limitations, the above-mentioned insights generated from studying the labor market impact of banking crises in developed countries around the world offer food for thought. Governments not only have to deal with the direct consequences of banking crises, but most governments are also in the midst of reforming labor markets to deal with ageing populations. These reforms are not only inspired by traditional demographic forces, but also because governments are trying to lengthen the working life in order to make public pension systems financially sustainable (Blundell et al., 2016; Henkens et al., 2018). Jaimovich and Siu (2009) show how ageing labor markets can have a strong impact on business cycle fluctuations and as societies age they may become less flexible as labor market institutions are still based on a demography of the distant past. The key question for the future is how economies will recover from recessions or depressions as the impact has to be borne by someone. Traditionally, the young are the ones who suffer most from economic downturns, but when this group becomes smaller, the impact of crises has to be borne by older participants. This may increase the costs from recovery as the older workers generally have more firm-specific human capital, whereas the young are still involved in their search for a good job/profession match (Gervais et al., 2016) and switching jobs is less costly provided unemployment duration is limited. Our study shows how in the recent past labor markets have adapted to banking crises. The current study suggests that extensive and strict employment protection may have short-run protection but in the medium-run it can be a burden as the unemployment rate among the young and middle-aged increases. This is in strong contrast to countries that are more flexible and offer little protection. The policy implications of these labor market outcomes in response to banking crises are on the one hand self-evident, as they demonstrate the importance of preventing banking crises in terms of regulation and monetary policy. The evidence of the impact of crises on youth unemployment rate show that these can be large and long-lasting (cf. Bruni et al., 2017). On the other hand, the implications are more complex for those countries that offer extensive and strict employment protection. Simply reforming those institutions by dismantling them may offer no solace. Instead those countries have to be aware that employment protection has to be complemented by fiscal efforts to moderate macroeconomic fluctuations in the aftermath of a banking crisis and more so than countries that offer little protection (see also Kawaguchi and Murao, 2014, p. 113).

\section{CRediT authorship contribution statement}

Mathijs A. van Dijk: Conceptualization, Methodology, Formal analysis, Investigation, Resources, Writing - review \& editing. Hendrik P. van Dalen: Conceptualization, Writing - original draft. Martin Hyde: Conceptualization, Resources, Writing - review \& editing.

\section{Declaration of Competing Interest}

The authors declare that they have no known competing financial interests or personal relationships that could have appeared to influence the work reported in this paper.

\section{Appendix A. Data description}

\section{Countries in dataset}

Our sample thus includes the following countries: Australia, Austria, Belgium, Bulgaria, Canada, Croatia, Czech Republic, Denmark, Estonia, Finland, France, Germany, Greece, Hungary, Iceland, Ireland, Israel, Italy, Japan, Latvia, Lithuania, Luxembourg, the Netherlands, New Zealand, Norway, Poland, Portugal, Romania, Singapore, Slovak Republic, Slovenia, South Korea, Spain, Sweden, Switzerland, Taiwan, the U.K., and the U.S.

\section{Labor force dataset}

The data for labor force participation rates by age and gender are available for the following age groups: $15+, 15-24,15-64,25-54$, 25-34, 35-54, 55-64 and 65+. We focus on the following five age groups relevant: 15-24, 25-34, 35-54, 55-64 and 65+ However, the data for unemployment rate by age and gender are only available in 10year age bands (15-24, 25-34, 35-44, 45-54, 55-64, 65+). Therefore, to ensure comparability between the two measures, we compute the unemployment rates for those aged 35-54. To do this, we use two additional data series from the ILO: the number of people who were unemployed by age and gender, and the number of people in the labor force by age and gender. These data series are also presented in 10-year age bands. We thus add the values for those aged 35-44 and those aged 45-54 to calculate the total number of people who are unemployed aged $35-54$ and the total number of people in the labor force aged 35-54. This then gives us the same age bands as for the labor force participation data. We then calculate the unemployment rate for all five age groups as the number of people who are unemployed as a percent of the total number of employed and unemployed people (i.e., the labor force). We compare the computed values for the age groups 15-24, 25-34, 55-64, and $65+$ against the values for the unemployment rate in the ILO dataset to ensure that they are accurate.

\section{References}

Aleksynska, M., Cazes, S., 2014. Comparing Indicators of Labour Market Regulations Across Databases: A Post Scriptum to the Employing Workers Debate. ILO, Geneva. Antonova, L., Bucher-Koenen, T., Mazzonna, F., 2017. Long-term health consequences of recessions during working years. Soc. Sci. Med. 187, 134-143. 
Axelrad, H., Sabbath, E.L., Hawkins, S.S., 2018. The 2008-2009 Great Recession and employment outcomes among older workers. Eur. J. Ageing 15, 35-45.

Bartelsman, E.J., Gautier, P.A., Wind, J., 2016. Employment protection, technology choice, and worker allocation. Int. Econ. Rev. 57 (3), 787-826.

Battiston, S., Farmer, J.D., Flache, A., Garlaschelli, D., Haldane, A.G., Heesterbeek, H., Hommes, C., Jaeger, C., May, R., Scheffer, M., 2016. Complexity theory and financial regulation. Science 351 (6275), 818-819.

Bennett, J., Möhring, K., 2015. Cumulative (dis) advantage? The impact of labour market policies on late career employment from a life course perspective. J. Soc. Policy 44 (2), 213-233.

Bernal-Verdugo, L.E., Furceri, D., Guillaume, D., 2013. Banking crises, labor reforms, and unemployment. J. Comparative Econ. 41 (4), 1202-1219.

Bertrand, M., Mullainathan, S., 2003. Enjoying the quiet life? Corporate governance and managerial preferences. J. Polit. Econ. 111 (5), 1043-1075.

Blanchard, O., Landier, A., 2002. The perverse effects of partial labour market reform: fixed-term contracts in France. Econ. J. 112 (480), 214-244.

Blanchard, O.J., Jaumotte, F., Loungani, P., 2014. Labor market policies and IMF advice in advanced economies during the Great Recession. IZA J. Policy 3 (1), 1-23.

Blundell, R., French, E., Tetlow, G., 2016. Retirement incentives and labor supply. In: Handbook of the Economics of Population Aging, pp. 457-566.

Boeri, T., Van Ours, J., 2013. The Economics of Imperfect Labor Markets. Princeton University Press.

Bruno, G.S., Choudhry Tanveer, M., Marelli, E., Signorelli, M., 2017. The short-and longrun impacts of financial crises on youth unemployment in OECD countries. Appl. Econ. 49 (34), 3372-3394.

Center for Systemic Peace, 2019. The Polity IV Project, database, Vienna, USA.

Chéron, A., Hairault, J.O., Langot, F., 2011. Age-dependent employment protection. Econ. J. 121 (557), 1477-1504.

Cho, Y., Newhouse, D., 2013. How did the great recession affect different types of workers? Evidence from 17 middle-income countries. World Dev 41, 31-50.

Claessens, S. and Kose, M.M.A., 2013. Financial crises explanations, types, and implications, IMF Working Paper No. 13/28, Washington DC.

Claessens, S., Kose, M.A., Terrones, M.E., 2009. What happens during recessions, crunches and busts? Econ. Policy 24 (60), 653-700.

Coile, C.C., Levine, P.B., 2007. Labor market shocks and retirement: Do government programs matter? J. Public Econ. 91 (10), 1902-1919.

Coile, C.C., Levine, P.B., 2011. The market crash and mass layoffs: How the current economic crisis may affect retirement. BE J. Econ. Anal. Policy 11 (1).

Dell'Ariccia, G., Detragiache, E., Rajan, R., 2008. The real effect of banking crises. J. Financial Intermed. 17 (1), 89-112.

Eggertsson, G.B., Krugman, P., 2012. Debt, deleveraging, and the liquidity trap: A FisherMinsky-Koo approach. Quart. J. Econ. 127 (3), 1469-1513.

EM-DAT (2019) 'The Emergency Events Database', Université catholique de Louvain (UCL) CRED, www.emdat.be, Brussels, Belgium.

Garloff, A., Pohl, C., Schanne, N., 2013. Do small labor market entry cohorts reduce unemployment? Demogr. Res. 29, 379-406.

Gervais, M., Jaimovich, N., Siu, H.E., Yedid-Levi, Y., 2016. 'What should I be when I grow up? Occupations and unemployment over the life cycle' J. Monetary Econ. 83, 54-70.

Gielen, A.C., Tatsiramos, K., 2012. Quit behavior and the role of job protection. Labour Econ. 19 (4), 624-632.

Gnocchi, S., Lagerborg, A., Pappa, E., 2015. Do labor market institutions matter for business cycles? J. Econ. Dyn. Control 51, 299-317.

Grigoli, F., Koczan, Z., Topalova, P., 2018. A Cohort-Based Analysis of Labor Force Participation for Advanced Economies: International Monetary Fund, Washington DC

Groot, S.P., Möhlmann, J.L., Garretsen, J.H., de Groot, H.L., 2011. The crisis sensitivity of European countries and regions: stylized facts and spatial heterogeneity. Cambridge J. Regions Econ. Soc. 4 (3), 437-456.

Henkens, K., van Dalen, H.P., Ekerdt, D.J., Hershey, D.A., Hyde, M., Radl, J., van Solinge, H., Wang, M., Zacher, H., 2018. What we need to know about retirement: Pressing issues for the coming decade. Gerontologist 58 (5), 805-812.

Hoynes, H., Miller, D.L., Schaller, J., 2012. Who suffers during recessions? J. Econ. Perspect. 26 (3), 27-47.

Inderbitzin, L., Staubli, S., Zweimüller, J., 2016. Extended unemployment benefits and early retirement: Program complementarity and program substitution. Am. Econ. J.:
Econ. Policy 8 (1), 253-288.

Jaimovich, N., Siu, H.E., 2009. The young, the old, and the restless: Demographics and business cycle volatility. Am. Econ. Rev. 99 (3), 804-826.

Kahn, L.M., 2007. The impact of employment protection mandates on demographic temporary employment patterns: International microeconomic evidence. Econ. J. 117 (521), 333-356.

Kahn, L.M., 2012. Labor market policy: A comparative view on the costs and benefits of labor market flexibility. J. Policy Anal. Manage. 31 (1), 94-110.

Karanikolos, M., Mladovsky, P., Cylus, J., Thomson, S., Basu, S., Stuckler, D., Mackenbach, J.P., McKee, M., 2013. Financial crisis, austerity, and health in Europe. Lancet 381 (9874), 1323-1331.

Kawaguchi, D., Murao, T., 2014. Labor-market institutions and long-term effects of youth unemployment. J. Money Credit Banking 46 (S2), 95-116.

Keeley, B., Love, P., 2010. From Crisis to Recession: The Causes, Course and Consequences of the Great Recession. OECD, Paris.

Korenman, S., Neumark, D., 2000. Cohort crowding and youth labor markets: A crossnational analysis. In: Blanchflower, D.G., Freeman, R.B. (Eds.), Youth Employment and Joblessness in Advanced Countries. University of Chicago Press, Chicago, pp. $57-106$.

Kroszner, R.S., Laeven, L., Klingebiel, D., 2007. Banking crises, financial dependence, and growth. J. Financ. Econ. 84 (1), 187-228.

Krueger, A.B., 2017. Where have all the workers gone? An inquiry into the decline of the US labor force participation rate. Brookings Papers Econ. Activity 2017 (2), 1-87.

Laeven, L., 2011. Banking crises: A review. Ann. Rev. Finan. Econ. 3 (1), 17-40.

Laeven, L., Valencia, F., 2013a. Systemic banking crises database. IMF Econ. Rev. 61 (2), 225-270.

Laeven, L., Valencia, F., 2013b. Resolution of banking crises. In: Caprio, G. (Ed.), Handbook of Safeguarding Global Financial Stability - Political, Social, Cultural, and Economic Theories and Models. Elsevier, New York, pp. 231-258.

Martin, J.P., Scarpetta, S., 2012. Setting it right: Employment protection, labour reallocation and productivity. De Economist 160 (2), 89-116.

Mian, A., Sufi, A., Trebbi, F., 2014. Resolving debt overhang: political constraints in the aftermath of financial crises. Am. Econ. J.: Macroecon. 6 (2), 1-28.

Mortensen, D.T., Pissarides, C.A., 1999. Job reallocation, employment fluctuations and unemployment. Handbook Macroecon. 1, 1171-1228.

Reinhart, C.M., Reinhart, V.R., Rogoff, K.S., 2012. Public debt overhangs: advancedeconomy episodes since 1800. J. Econ. Perspect. 26 (3), 69-86.

Reinhart, C.M., Rogoff, K.S., 2009a. The aftermath of financial crises. Am. Econ. Rev. 99 (2), 466-472.

Reinhart, C.M., Rogoff, K.S., 2009b. This Time is Different: Eight Centuries of Financial Folly. Princeton University Press.

Reinhart, C.M., Rogoff, K.S., 2011. From financial crash to debt crisis. Am. Econ. Rev. 101 (5), 1676-1706.

Romer, C.D., Romer, D.H., 2018. Phillips Lecture-Why Some Times Are Different: Macroeconomic Policy and the Aftermath of Financial Crises. Economica 85 (337), $1-40$.

Scarpetta, S., Sonnet, A., Manfredi, T., 2010. Rising Youth Unemployment during the Crisis: How to Prevent Negative Long-term Consequences on a Generation?, OECD Social, Employment and Migration Working Papers, No. 106, Paris.

Shimer, R., 2001. The impact of young workers on the aggregate labor market. Quart. J. Econ. 116 (3), 969-1007.

Szinovacz, M.E., Davey, A., Martin, L., 2015. Did the great recession influence retirement plans? Res. Aging 37 (3), 275-305.

Tanveer Choudhry, M., Marelli, E., Signorelli, M., 2012. Youth unemployment rate and impact of financial crises. Int. J. Manpower 33 (1), 76-95.

Van Dalen, H.P., Henkens, K., 2013. Dilemmas of downsizing during the Great Recession: Crisis strategies of European employers. De Economist 161 (3), 307-329.

Van Zandweghe, W., 2012. Interpreting the recent decline in labor force participation. Economic Review, Federal Reserve Bank of Kansas City, 5-34

Venn, D., 2009. Legislation, Collective Bargaining and Enforcement: Updating the OECD Employment Protection Indicators, 1815-199X, Paris, OECD.

Worldbank, 2017. 'Database of political institutions', Washington DC, Worldbank.

Zingales, L., 2015. Presidential address: Does finance benefit society? J. Finance 70 (4), 1327-1363. 